\section{Antidepressants and pregnancy}

In her commentary, Einarson ${ }^{1}$ discusses a study by Nakhai-Pour and colleagues that found an increased rate of spontaneous abortion with antidepressant use in pregnancy. ${ }^{2}$ Einarson found similarly increased risks in a 2009 study of women who contacted teratology information centres. ${ }^{3}$ Despite this replication, she casts doubt on Nakhai-Pour and colleagues' results, stating that "this study cannot make any definitive conclusion as to whether antidepressants increase the risk of spontaneous abortion," and that "if there is a true increased risk of spontaneous abortion caused by gestational use of antidepressants, it is very small."'

Einarson fails to mention a single strength of the study, such as the large population-based sample, prospective recording of filled prescriptions, and controls for potential confounders such as socioeconomic status, comorbidities and indicators of depression severity. She also raises doubts about statistical significance, citing an expected 5\% false-positive rate and over 100 analyses. We counted 15 analyses; of these, 13 crude and 7 adjusted ORs were significant $(p<0.05)$. Thus, even with a $5 \%$ type I error, the association between antidepressant use and increased risk of spontaneous abortion appears robust.

The relation between antidepressants and spontaneous abortion meets many of Bradford-Hill's epidemiologic criteria for causation, such as biologic plausibility, dose-response, temporal sequence and replication.

We disagree with Einarson's characterization of the absolute risk increase of $2.8 \%$ (unadjusted) and relative increase of 1.68 (95\% confidence interval 1.38-2.06) as "very small" and unconfirmed. Moreover, there is evidence linking antidepressants to cardiac defects, persistent pulmonary hypertension and a neonatal syndrome. ${ }^{4}$

Women facing depression in pregnancy need accurate and unbiased information on treatment efficacy. For mild to moderate major depression, efficacy of antidepressants differs little from that of placebo. ${ }^{5.6}$ Nondrug treatments such as psychotherapy do not have the same potential for harm; they should be offered first line.

\section{Barbara Mintzes PhD}

Assistant professor, Department of

Anesthesiology, Pharmacology \&

Therapeutics, Therapeutics Initiative,

University of British Columbia,

Vancouver, BC

\section{Elia Abi-Jaoude MD}

Research fellow, Department of

Psychiatry, University of Toronto,

Toronto, Ont.

\section{Anne Rochon Ford}

Coordinator, Women and Health

Protection, Toronto, Ont.

\section{References}

1. Einarson A. Antidepressants and pregnancy: complexities of producing evidence-based information. CMAJ 2010;182:1017-8.

2. Nakhai-Pour HR, Broy P, Berard A. Use of antidepressants during pregnacy and the risk of spontaneous abortion. CMAJ 2010;182:1031-7.

3. Einarson A, Choi J. Einarson TR, et al. Rates of spontaneous and therapeutic abortions following use of antidepressants in pregnancy: results from a large prospective database. J Obstet Gynaecol Can 2008;31:452-6.

4. Tuccori M, Testi A, Antonioli L, et al. Safety concerns associated with the use of serotonin reuptake inhibitors and other serotonergic/noradrenergic antidepressants during pregnancy: a review. Clin Ther 2009;31 Pt 1:1426-53.

5. Kirsch I, Deacon BJ, Huedo-Medina TB, et al. Initial severity and antidepressant benefits: a metaanalysis of data submitted to the Food and Drug Administration. PLoS Med 2008;5:e45.

6. Fournier JC, DeRubeis RJ, Hollon SD, et al. Antidepressant drug effects and depression severity: a patient-level meta-analysis. JAMA 2010;303:47-53.

CMAJ 2011. DOI:10.1503/cmaj.111-2027

I thank Mintzes and associates for their comments. I should have stated that neither study by Nakhai-Pour and colleagues ${ }^{1}$ or Motherisk ${ }^{2}$ could make any definitive conclusions, although I stand by my comment that "if there is a true increased risk of spontaneous abortion caused by gestational use of antidepressants, it is very small." ${ }^{3}$

The small risk referred to was the odds ratio $(\mathrm{OR})$ of 1.68 ; it is well known among epidemiologists that ORs of less than 2 are problematic. ${ }^{3}$ Observational studies have inherent biases that cannot be removed with certainty. Although the authors addressed some of the issues, it is impossible to identify and remove the influence of all factors, since many remain unknown; there is still a possibility of a false-positive result.

In my commentary, I focused on antidepressants and spontaneous abortion and discussed Nakhai-Pour and colleagues' study. I do not feel it is appropriate that Mintzes and associates mention other outcomes, quoting from a review that is no longer current. ${ }^{5}$ It is also inappropriate to talk about treatment efficacy, since I did not mention this in my commentary. At Motherisk, we conduct research to evaluate the safety and risk of a particular drug during pregnancy only, not to examine the efficacy of treatment. The latter should be left to the prescribing physician, who is frequently faced with an already pregnant woman taking an antidepressant and requiring treatment. Is it reasonable to advise such a patient to stop treatment and switch to psychotherapy?

I agree that women facing depression during pregnancy need accurate and unbiased information on the use of antidepressants. After reviewing all the evidence, each woman, with her physician, needs to make an informed decision about whether to take the medication.

\section{Adrienne Einarson RN}

Assistant director, The Motherisk

Program, Division of Clinical

Pharmacology, University of Toronto, Toronto, Ont.

\section{References}

1. Nakhai-Pour HR, Broy P, Berard A. Use of antidepressants during pregnacy and the risk of spontaneous abortion. CMAJ 2010;182:1031-7.

2. Einarson A, Choi J. Einarson TR, et al. Rates of spontaneous and therapeutic abortions following use of antidepressants in pregnancy: results from a large prospective database. J Obstet Gynaecol Can 2008;31:452-6.

3. Einarson A. Antidepressants and pregnancy: complexities of producing evidence-based information CMAJ 2010;182:1017-8.

4. Straus SE, Richardson WS, Glasziou P, et al. Evidence-based medicine: how to practice and teach EBM. 3rd ed. St. Louis (MO): Turtleback Books; 2005

5. Tuccori M, Testi A, Antonioli L, et al. Safety concerns associated with the use of serotonin reuptake inhibitors and other serotonergic/noradrenergic antidepressants during pregnancy: a review. Clin Ther 2009;31 Pt 1:1426-53.

CMAJ 2011. DOI:10.1503/cmaj.111-2028 